\title{
Condition Assessment on Thermal Effects of a Suspension Bridge Based on SHM Oriented Model and Data
}

\author{
Bo Chen, ${ }^{1}$ Zhi-wei Chen, ${ }^{2}$ Yu-zhou Sun, ${ }^{3}$ and Sheng-lin Zhao ${ }^{1}$ \\ ${ }^{1}$ Key Laboratory of Roadway Bridge and Structural Engineering, Wuhan University of Technology, Wuhan 430070, China \\ ${ }^{2}$ School of Architecture and Civil Engineering, Xiamen University, Xiamen 361005, China \\ ${ }^{3}$ School of Civil Engineering and Architecture, Zhongyuan University of Technology, Zhengzhou 450007, China
}

Correspondence should be addressed to Bo Chen; cbsteven@163.com

Received 9 October 2013; Accepted 6 November 2013

Academic Editor: Ting-Hua Yi

Copyright (C) 2013 Bo Chen et al. This is an open access article distributed under the Creative Commons Attribution License, which permits unrestricted use, distribution, and reproduction in any medium, provided the original work is properly cited.

\begin{abstract}
This paper aims to carry out the condition assessment on temperature distribution and thermal effects of a long span suspension bridge. The structural health monitoring (SHM) oriented data analysis is first performed and several indices are developed to process the time-varying temperature, displacement, and strain responses. An analytical procedure based on heat transfer theory is presented to determine the temperature distributions within the bridge. The fine finite element models of the deck plate, the cross frame, and the bridge tower are constructed for thermal analysis. A new approach to the thermal-structural coupling analysis of long span bridges is proposed to examine the structural thermal effects. The feasibility and validity of the proposed data process method and the new approach for thermal-structural coupling analysis are examined through detailed numerical simulation. The numerical results are compared with the field measurement data obtained from the long-term monitoring system of the bridge and they show a very good agreement, in terms of temperature distribution in different time and in different seasons. This exercise verifies the accuracy of the heat transfer analysis employed and the effectiveness and validity of the proposed approaches for data processing and thermal-structural coupling analysis.
\end{abstract}

\section{Introduction}

Long span bridges are subjected to thermal effects due to the interaction with the environmental conditions. The interaction with air temperature and solar radiation leads to seasonal and daily temperature changes in the bridges. Temperature variations in bridges may induce the structural movement and thermal stresses due to the indeterminacy, which may cause the damage events of the structural components, even the entire bridge [1-3]. Thermal effects on long span bridges have been investigated across the world to simulate the temperature distribution of bridges and predict the structural responses by establishing one-dimensional to three-dimensional finite element (FE) models. Zuk [4] investigated the thermal behaviour of several highway bridges and found that the temperature distribution was affected by many factors such as air temperature, wind, humidity, intensity of solar radiation, and material type. Capps [5] measured temperature and longitudinal movements of a steel box bridge in the UK. Churchward and Sokal [6] instrumented a section of poststressed concrete bridge for recording temperature profiles at different instants of time. The structural temperature distribution and thermal variations have also been examined based on computer models with the aid of FE model since 1970s [7]. The effects of solar radiation, convex, conduction, heat of hydration, member size, and geometry have been taken into consideration. Elbadry and Ghali [8] examined the temperature distribution and estimated stresses of a concrete bridge by developing a two-dimensional FE model. Branco and Mendes [9] proposed an approach to define temperature design values for concrete bridges. Based on a numerical technique, the results of a parametric study were developed for the evaluation of design values for temperature differences in small and medium span bridges located in Portugal.

The field measurement and monitoring of temperature distribution and thermal effects of bridges have been widely carried out in recent years due to the rapid development and application of structural health monitoring (SHM) 
technology. Shahawy and Arockiasamy [10] compared the measured time-dependent strains of the Sunshine Skyway Bridge with the analytical predictions. Roberts-Wollman et al. [11] compared the calculated and measured deflections of a box girder bridge. Fu and DeWolf [12] carried out field measurement and numerical simulation on a curved concrete bridge concerning the temperature effects on the tilt and natural frequencies. Desjardins et al. [13] studied modal data and average girder temperature collected over a six-month period in the Confederation Bridge. Tong et al. $[14,15]$ and $\mathrm{Au}$ et al. [16] carried out similar investigations for both composite bridges and steel bridges. They also carried out a laboratory study and a field study on the Tsing Ma Bridge to verify the heat conduction models. Wong et al. $[17,18]$ introduced a 3 -year thermal monitoring and response monitoring of the Ting Kau Bridge. Xu et al. [19] investigated the temperatureinduced displacement responses of Tsing Ma Bridge based on field monitoring data from 1997 to 2005.

The configurations and performance of long span bridges such as suspension bridges are quite different from those of common concrete bridges. For long span bridges, the current research focuses on field monitoring of the temperature and bridge displacement only. There have been few studies on the evaluation of thermal effects of long span bridges based on SHM oriented bridge model. The feature extraction and data mining on the thermal monitoring information of bridges are very rare. Consequently, the SHM oriented feature extraction and condition assessment on the thermal effects of long span bridges are very limited [20].

To this end, the condition assessment on temperature distribution and thermal effects of a long span suspension bridge are carried out by taking the Tsing Ma Suspension Bridge as an example structure. The SHM oriented data analysis is first performed by proposing a data processing technique based on empirical mode decomposition (EMD). Several indices are developed to process the time-varying temperature, displacement, and strain responses collected by SHM system. An analytical procedure based on heat transfer theory is presented to determine the temperature distributions within the bridge. Several FE models are constructed for deck plates and bridge sections to compute the temperature distribution, which are used to calculate the bridge thermal displacement and thermal stress. A new approach for the thermal-structural coupling analysis of long span bridges is proposed to examine the structural thermal effects. The feasibility and validity of the proposed data process approach and the new approach for thermalstructural coupling analysis are examined through detailed simulation. The made observation indicates that the simulated temperature distribution and effects of the bridge are in good agreement with those from field measurement.

\section{Bridge Configuration and Health Monitoring System}

2.1. Bridge Configuration. Located at latitude $\mathrm{N} 22.2^{\circ}$ and longitude E114.1 $1^{\circ}$, Tsing Ma Suspension Bridge has a total span of $2132 \mathrm{~m}$ and carries a dual three-lane highway on the upper level of the bridge deck and two railway tracks and two protected carriageways at the lowest level within the bridge deck. The main span across the Tsing Yi island and the Ma Wan island has $1377 \mathrm{~m}$ long, as shown in Figure 1. The angle between the bridge longitudinal axis and the south is $73^{\circ}$. The height of the two reinforced concrete bridge towers, the Tsing Yi tower and the Ma Wan tower, is about $206 \mathrm{~m}$, measured from the base level to the tower saddle. The two main cables of $36 \mathrm{~m}$ apart in the north and south are accommodated by the four saddles located at the top of the tower legs. The diameter of the main cables is $1.0 \mathrm{~m}$. The lengths of the Tsing Yi side span and the Ma Wan side span are $300 \mathrm{~m}$ and $455 \mathrm{~m}$, respectively. The structural translational movements at the Ma Wan abutment are restrained in three translational directions. At the Tsing Yi abutment, the vertical $(z$-axis) and lateral ( $y$-axis) movements of the bridge deck are restrained while the deck can move freely along the longitudinal direction ( $x$-axis).

The bridge deck at the main span is a suspended deck type. Figure 2 illustrates the configuration of an $18 \mathrm{~m}$ long typical suspended deck module, which includes a main cross frame and four neighbouring intermediate cross frames. The five cross frames of $4.5 \mathrm{~m}$ apart from each other are connected by two outer longitudinal trusses. Two symmetrical bays of top orthotropic deck plates are connected to the top chords of the cross frames, and the decks are constructed with a row of the central cross bracing. Regarding the bottom deck, there are two railway tracks laid on the central bay of the deck in addition to two bays of orthotropic deck plates on the two outer sides that are all supported on the bottom chords of the cross frames. There are two rows of outer cross bracings added to brace the bottom chords of the cross frames and separate the orthotropic deck plate and railway track. Another kind of bracing, namely, sway bracing, is used to brace the main cross frame from the two adjacent intermediate cross frames.

2.2. Health Monitoring System. A wind and structural health monitoring system (WASHMS) for the Tsing Ma Bridge has been devised, installed, and operated by the HighWays Department of the Government of Hong Kong Special Administrative Region (HKSAR) since 1997. The WASHMS is composed of five subsystems, namely, sensory system, data acquisition system, data processing and analysis system, computer for system operation and control, and fiber optic cabling network system [17]. About 280 sensors, including anemometers, temperature sensors, accelerometers, strain gauges, level sensing stations, displacement transducers, weigh-in-motion stations, and GPS receivers, were installed at different locations on the bridge for collecting various types of structural and environmental information.

The position of the temperature sensors on the Tsing Ma Bridge is shown in Figure 1. The collected temperature data from WASHMS can be grouped into three categories: (1) ambient temperature ( $T 1$ and $T 2)$; (2) section temperature (T3 and T4); and (3) cable temperature (T5, T6, and T7). One air temperature sensor (Ch. 81, T1) is approximately at the middle section of the main span and attached to a sign gantry which stands on the upper deck. The other five 


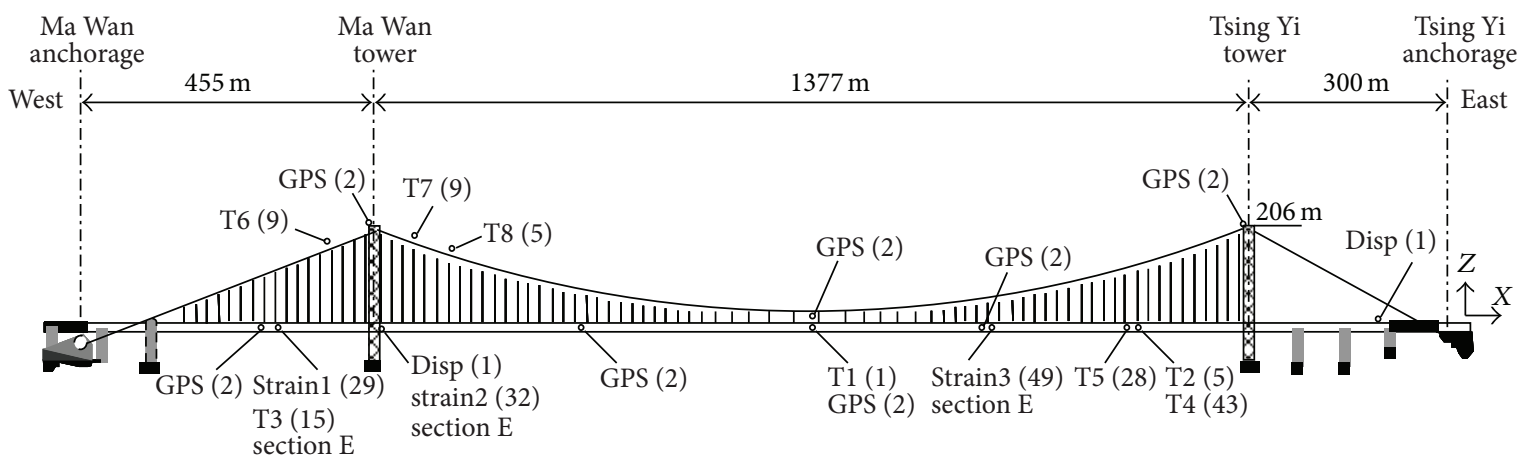

FIgURE 1: Configuration and sensor layout of the Tsing Ma Suspension Bridge.



FIGURE 2: Configuration of a suspended deck module (unit: $\mathrm{m}$ ).

air temperature sensors (Ch. 82 to Ch. $86, T 2)$ measure the ambient temperature inside the bridge deck section of the main span near the Tsing Yi tower. 23 thermocouples (T5, T6, and T7) were embedded inside the main cables at three different locations to measure the cable temperature.

The deck section in the Ma Wan side span is equipped with 15 sensors (T3) and another deck section close to the Tsing Yi tower is equipped with 71 sensors (T4). Figure 3 illustrates seven groups of temperature sensors (details 10 to 16,28 sensors in total) mounted on the orthotropic deck plates $2.25 \mathrm{~m}$ away from the section. At each detail, one sensor measures the temperature of steel plate and the other three sensors measure the temperature distribution over the deck trough. In addition, there are four temperature sensors mounted on diagonal bracing members between adjacent cross frames and two temperature sensors installed on the corrugated sheets on south side of the bridge section, which are not shown here for brevity. The sampling frequency of all of the temperature sensors is $0.07 \mathrm{~Hz}$.

The displacements of the bridge in the three orthogonal directions: (1) longitudinal ( $x$-direction); (2) lateral ( $y$ direction); and (3) vertical ( $z$-direction), are recorded by using displacement transducers and GPS stations. As shown in Figure 1, one displacement transducer is installed in the north side of a bearing frame which sits on the lowest portal beam of the Ma Wan tower with bearing connection. The longitudinal movement of the bridge deck at the Tsing Yi abutment is recorded by another displacement transducer, which is underneath the expansion joint bearing and attached between the Tsing Yi abutment and the bottom chord of 


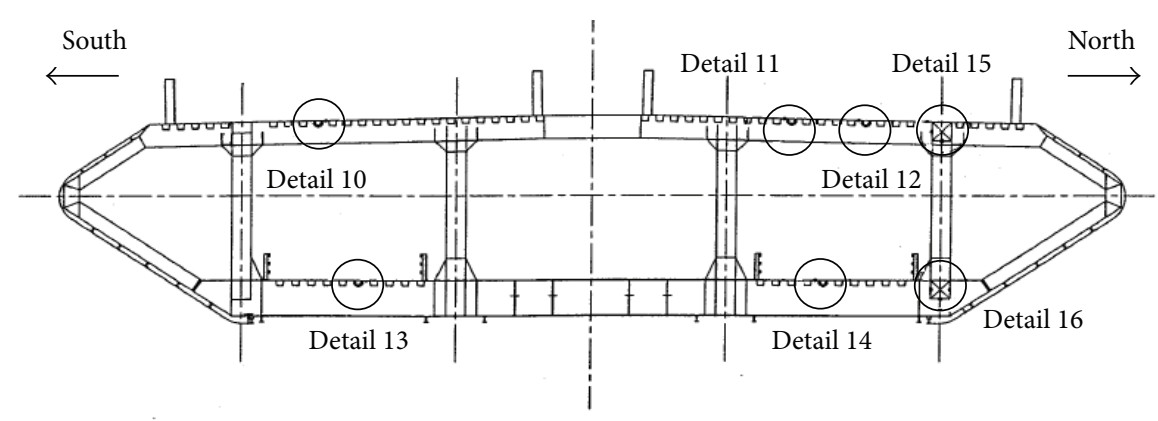

FIgURe 3: Position of temperature sensors on the deck plate (T4).

a cross frame next to the abutment to measure the displacement of the deck section. The components of the bridge implemented with the GPS receivers include bridge towers, main cables, and bridge deck. Two base reference stations sit at a storage building adjacent to the bridge monitoring room. The Ma Wan tower and Tsing Yi tower are, respectively, installed with a pair of GPS receivers, and they are mounted at the top of saddles on each of the tower legs. The displacement of the main cables is monitored through a pair of GPS receivers at the midspan. The midspan of the Ma Wan side span is equipped with a pair of receivers. Three pairs of GPS receivers are located at one quarter, one half, and three quarters of the main span of the bridge deck. It is seen from Figure 1 that 110 strain gauges have been installed at three deck sections of the Tsing Ma Bridge. Taking Section E as an example, 32 strain gauges were installed at the longitudinal truss near the Ma Wan tower. The outer and inner trusses were equipped with four pairs of gauges (denoted as SP) and two single gauges (denoted as SS).

\section{SHM Oriented Data Analysis}

3.1. Signal Processing Based on EMD. The response signals can be processed by using empirical mode decomposition (EMD) [21]. As a new signal processing method, the EMD can decompose any data set into several intrinsic mode functions (IMFs) by a procedure called sifting process. Suppose $x(t)$ is a time history to be decomposed. The sifting process is conducted by first constructing the upper and lower envelopes of $x(t)$ by connecting its local maxima and local minima through a cubic spline. Designate the mean value of the two envelopes as $m_{1}(t)$ and compute the difference between the original time history and the mean value

$$
h_{1}(t)=x(t)-m_{1}(t) \text {. }
$$

The component $h_{1}(t)$ is then examined to see if it satisfies the requirements to be an IMF. If not, the sifting process is to be repeated by treating $h_{1}(t)$ as a new time history until $h_{1}(t)$ is an IMF, designated as $c_{1}(t)$. Then, the first IMF is separated from the original time history, giving a residue $r_{1}(t)$ as

$$
r_{1}(t)=x(t)-c_{1}(t)
$$

The sifting process is applied successively to each subsequent residue to obtain the subsequent IMFs until either the residue $r_{n}(t)$ is smaller than a predetermined value or it becomes a monotonic function. The original time history is finally expressed as the sum of the IMF components plus the final residue

$$
x(t)=\sum_{j=1}^{n} c_{j}(t)+r_{n}(t),
$$

where $c_{j}(t)$ is the $j$ th IMF component; $n$ is the total number of IMF components; and $r_{n}(t)$ is the final residue. After the decomposition, the first IMF component obtained has the highest frequency content of the original time history while the final residue represents the component of the lowest frequency in the time history.

\subsection{Feature Extraction and Analysis on Strain Data. Figure 4} illustrates the position of six strain gauges (four SP types and two SS types) at the north inner truss. Displaced in Figure 5 are the time histories of axial strain between 12:00 AM to 13:00 PM for strain gauge SPTEN04. It is seen that there exist several spikes with large amplitude which are induced by running trains. The measured time histories may include the effects of vehicles. In addition, it can be seen that the time histories at other time durations are quite similar to that the noon. Thus, this signal $x^{s}(t)$ is decomposed by using EMD and 13 IMFs can be obtained as shown in Figure 6

$$
x^{s}(t)=\sum_{j=1}^{n s} c_{j}^{s}(t)+r_{n s}^{s}(t),
$$

where $c_{j}^{s}(t)$ is the $j$ th IMF component of the strain response; $n s$ is the total number of IMF components of strain response; and $r_{n s}^{s}(t)$ is the final residue.

The signal is decomposed with EMD without using intermittency check and thereby the cut-off frequency is not required in the sifting process. It is known from the principles of the EMD that the IMF with the highest frequency components will be extracted first from the original signal and the IMF with the lowest frequency components is extracted finally. Figure 6 displays the time histories of IMFs and residue, and the Fourier spectrum of each component is displayed in Figure 7. The statistical values of all the IMFs and residue are listed in Table 1. It can be found from Figure 6 that the magnitude of the first four IMFs is quite small in 


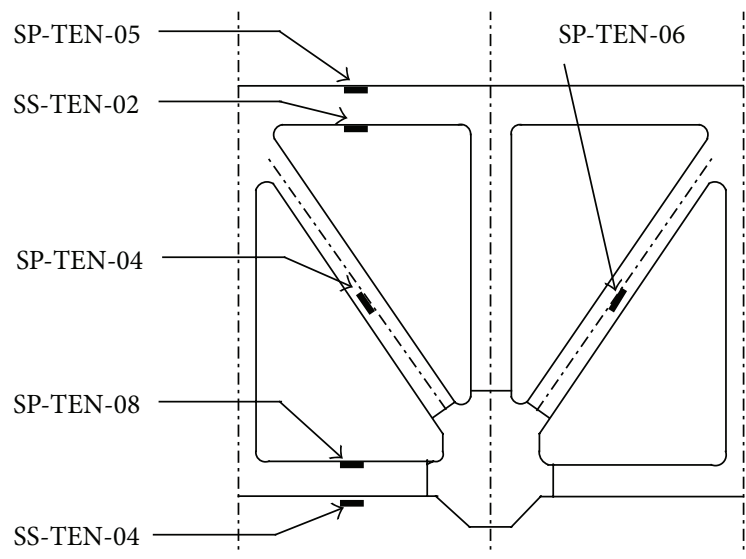

FIGURE 4: Strain gauges at north inner longitudinal truss.



Figure 5: Time histories of axial strain between 12:00 AM and 13:00 PM.

comparison with that of the other IMFs. Similar observations can be made from the spectrum amplitude of the first four IMFs as shown in Figure 7. In addition, it is seen that the frequency range of the first four IMFs is much wider than that of other signal components. The data in Table 1 indicate that the mean values of the first four IMFs are close to zero and their amplitudes are very small. Therefore, it is clear that the first four IMFs are the noise components in the original strain time histories.

The middle eight IMFs (IMF5 to IMF12) have very small mean value while their time histories exist obvious signal fluctuation. Many spikes with large amplitudes can also be observed in the time histories of these IMFs as shown in Figure 6. Because the varying ambient temperature in the Tsing Ma Bridge in an hour is small, therefore the thermal-induced structural responses may change very slowly and the corresponding responses mainly include low frequency components. Therefore, the middle eight IMFs are the signal components induced by traffics and other dynamic excitations such as wind. The Fourier spectrum of the eight IMFs displayed in Figure 7 demonstrates that the dynamic loading dominates the frequency range of $0.001 \sim$ $0.08 \mathrm{~Hz}$. The frequency component higher than $0.08 \mathrm{~Hz}$ can be regarded as noise, and the low frequency component with little variation is regarded as the static displacement because of the dead load. The sum of last IMF and residue can be taken as the effects of gravity and thermal loading. Because the gravity loading of the bridge is not changed commonly, the hourly variation of thermal effects can be computed. Therefore, the strain responses of the bridge can
TABLE 1: Statistical values of IMFs and residue.

\begin{tabular}{lccc}
\hline Number & Mean & $\begin{array}{c}\text { Maximum absolute } \\
\text { value }\end{array}$ & Standard deviation \\
\hline IMF 1 & $-7.5424 E-4$ & 1.31275 & 0.24134 \\
IMF 2 & $-7.09953 E-5$ & 1.73038 & 0.20125 \\
IMF 3 & $1.90728 E-4$ & 1.17978 & 0.19486 \\
IMF 4 & $-3.32764 E-4$ & 0.90878 & 0.15156 \\
IMF 5 & -0.01426 & 9.93309 & 0.68445 \\
IMF 6 & -0.02884 & 8.74782 & 1.78688 \\
IMF 7 & 0.11534 & 30.5291 & 5.68814 \\
IMF 8 & -0.08829 & 36.2402 & 6.90871 \\
IMF 9 & 0.36278 & 17.0608 & 4.76462 \\
IMF 10 & 0.06263 & 7.10906 & 2.6422 \\
IMF 11 & -0.04511 & 2.57784 & 1.3094 \\
IMF 12 & -0.12939 & 1.29054 & 0.77235 \\
IMF 13 & -0.21269 & 1.95364 & 1.31424 \\
Residue & -16.0510 & 16.0519 & 0 \\
\hline
\end{tabular}

be decomposed firstly to reconstruct the noise component $x_{\text {noise }}^{s}(t)$, dynamic component $x_{\text {dyn }}^{s}(t)$, and static component $x_{\text {static }}^{s}(t)$, respectively, with the aid of spectrum analysis

$$
\begin{gathered}
x_{\text {noise }}^{s}(t)=\sum_{j=1}^{m s} c_{j}^{s}(t), \\
x_{\text {dyn }}^{s}(t)=\sum_{j=m s+1}^{n s-1} c_{j}^{s}(t), \\
x_{\text {static }}^{s}(t)=c_{n s}^{s}(t)+r_{n s}^{s}(t),
\end{gathered}
$$

where $m s$ is the total number of noise IMF components. If the absolute mean value of a particular IMF is quite small, this IMF can be regarded as noise component

$$
\operatorname{abs}\left(\operatorname{mean}\left(c_{j}^{s}(t)\right)\right)<\varepsilon_{m s},
$$

where $\operatorname{abs}()$ means to take the absolute value; $\varepsilon_{m s}$ is the threshold value of absolute mean value of a particular IMF component and can be set as $1 \times 10^{-3}$ for the strain responses of the example bridge (see Table 1).

Figures 8(a) and 8(b) display the strain responses induced by dynamic excitations $x_{\text {dyn }}^{s}(t)$ and static loading $x_{\text {static }}^{s}(t)$, respectively. It is also observed that some measurement data are associated with zero standard deviation. A zero standard deviation physically indicates that a steady value of measurement without any signal fluctuation is recorded within the statistical period considered. As a result, the statistical values of mean, maximum, and minimum having the same magnitude are correspondingly noted in this case. Having a perfectly flat signal is considered as an abnormal measurement. Correspondingly, the index to eliminate the abnormal data is set in terms of the zero standard deviation of any IMF component and is given by

$$
\operatorname{std}\left(c_{j}^{s}(t)\right)=0 .
$$





Figure 6: Time histories of IMFs and residue. 



FIGURE 7: Fourier spectrum of IMFs. 


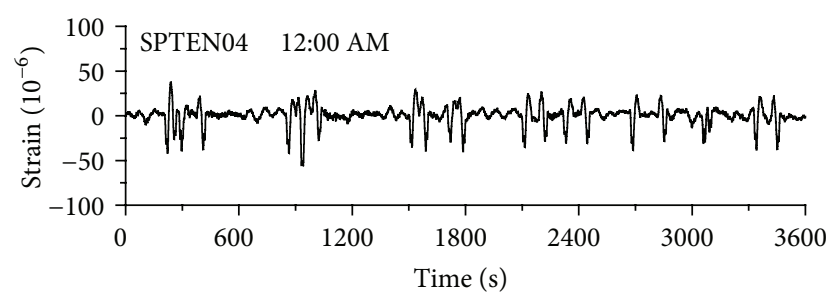

(a) Induced by dynamic traffics

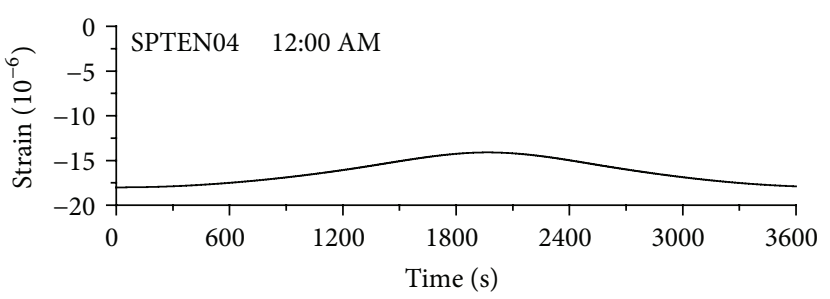

(b) Induced by temperature

FIGURE 8: Time histories of axial strain.

As far as the responses without demonstrating abnormal magnitude, there still is a possibility that the bridge responses with reasonable magnitude are induced by dynamic excitations such as traffics and strong winds instead of the temperature variation. Because the temperature variation would commonly induce static effects on the bridge responses, the structural dynamic responses affected by the temperature should be insignificant intuitively. Therefore, the standard deviation of measurement data is an effective indicator of dynamic effect and it would be very small for temperature induced bridge responses on an hourly basis in comparison with those induced by traffics and winds. Thus, a criterion based on the standard deviation of hourly measurement data can be selected as the indicating index and is expressed as

$$
\operatorname{std}\left(x_{\text {dyn }}^{s}(t)\right)>\xi_{s},
$$

where $\xi_{s}$ is the threshold value of standard deviation of a particular hourly strain response.

\subsection{Feature Extraction and Analysis on Temperature Data.} Similar to the signal processing of strain responses, the time history of the measured temperature can be decomposed by EMD

$$
x^{T}(t)=\sum_{j=1}^{n t} c_{j}^{T}(t)+r_{n t}^{T}(t),
$$

where $c_{j}^{T}(t)$ is the $j$ th IMF component of the temperature response; $n t$ is the total number of IMF components of temperature response; and $r_{n t}^{T}(t)$ is the final residue.

Because the dynamic loading cannot substantially affect the temperature responses of the bridge, the temperature responses of the bridge can be decomposed firstly to reconstruct noise component $x_{\text {noise }}^{T}(t)$ and nonnoise component $x_{t}^{T}(t)$, respectively, with the aid of spectrum analysis

$$
\begin{gathered}
x_{\text {noise }}^{T}(t)=\sum_{j=1}^{m t} c_{j}^{T}(t), \\
x_{t}^{T}(t)=\sum_{j=m t+1}^{n t} c_{j}^{T}(t)+r_{n t}^{T}(t),
\end{gathered}
$$

where $m t$ is the total number of IMF components of noise contamination.
The instrument malfunction may induce the abnormal information in the measurement data sets. In the collected statistical data, data with extremely large or small magnitude are a typical case considered to be the abnormal data. The observed extreme values are usually unrealistic, and this case can be checked from the hourly maximum and/or minimum values which are largely different from the normal data. Thus, the first index to eliminate the abnormal data is set in terms of difference between the hourly maximum and minimum values and is expressed as

$$
\operatorname{abs}\left(x_{t, \max }^{T}-x_{t, \min }^{T}\right)>\varepsilon_{T},
$$

where $\operatorname{abs}()$ means to take the absolute value; $x_{t, \max }^{T}$ and $x_{t, \text { min }}^{T}$ denote the hourly maximum and minimum temperature value, respectively; $\varepsilon_{T}$ is a real number defining the limit of the difference between the maximum and minimum values under the normal temperature loading environment and is selected as $5^{\circ} \mathrm{C}$ for the example bridge.

In reality, the temperature of Hong Kong is within a certain range and an extremely low temperature recorded by the temperature sensor does not have any physical meaning. Having a temperature signal with extremely low value is considered as an abnormal measurement. Therefore, the second index is set in order to eliminate the extreme low data from temperature information [19]

$$
x_{t}^{T}(t)<T_{\min }
$$

where $T$ denotes the hourly mean value of temperature; $T_{\min }$ is a real number, which defines the threshold value of minimum temperature which is selected as $-5^{\circ} \mathrm{C}$ in this study for Hong Kong situation. Similar to that for strain responses, the standard deviation can be utilized to eliminate the abnormal measurement data having a perfectly flat signal

$$
\operatorname{std}\left(c_{j}^{T}(t)\right)=0
$$

As discussed above, temperature variation in an hour would not be intensive and the standard deviations of measured temperature would be very small. Thus, an index based on the standard deviation of hourly temperature responses can be selected to eliminate the abnormal temperature data induced by instrument malfunction

$$
\operatorname{std}\left(x_{t}^{T}(t)\right)>\xi_{T}
$$



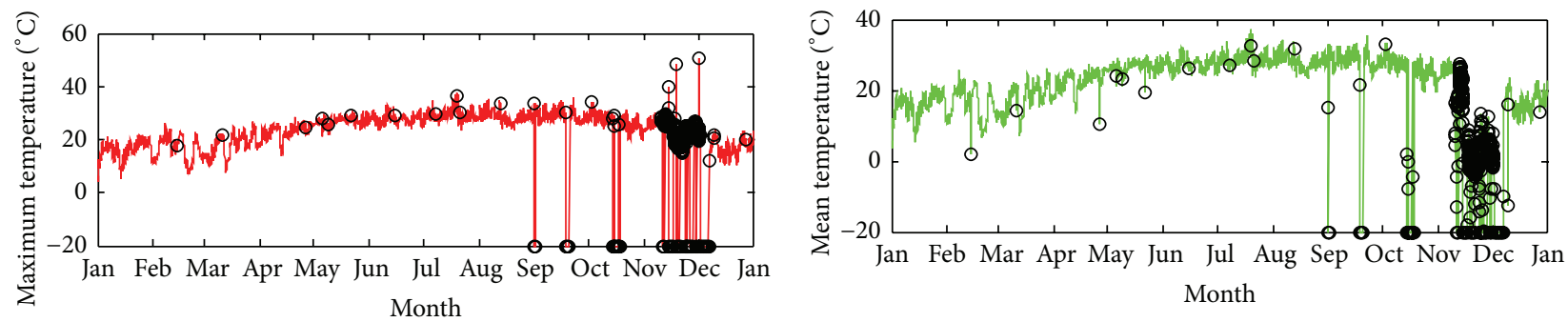

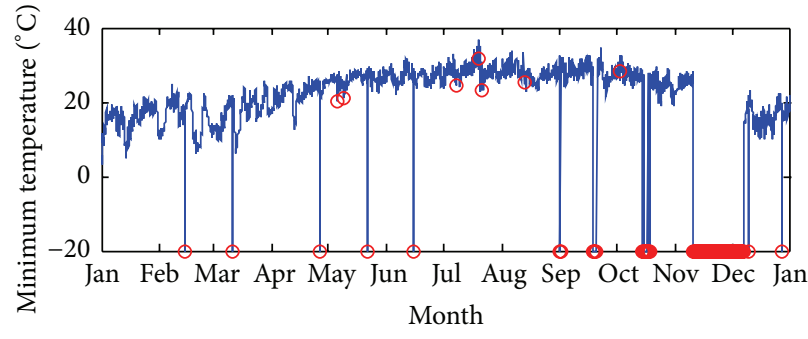

(a) Maximum and minimum temperature

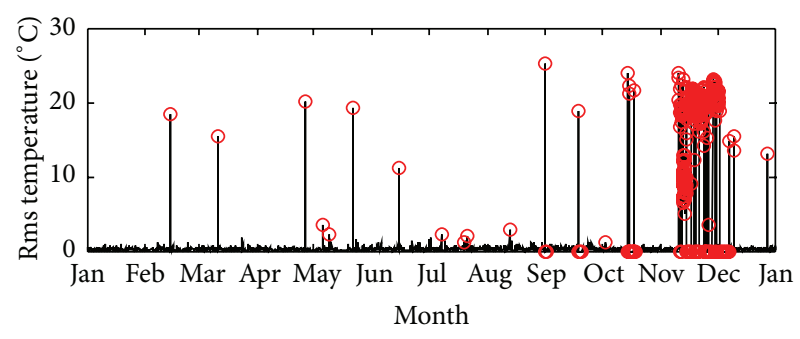

(b) Mean and rms temperature

FIGURE 9: Hourly ambient temperature in 2005 from the sensor with channel number 81.

where $\xi_{T}$ is the threshold value of standard deviation of a particular hourly temperature response and is set as $2^{\circ} \mathrm{C}$ for the example bridge.

Evaluation of the elimination performance for temperature data from the sensor with channel number 81 , which is installed on a sign gantry for ambient temperature measurement in the middle of the main span, can be seen in Figures 9(a) and 9(b). The temperature time histories in terms of the four statistical values maximum, minimum, mean, and root mean square (rms) in the year of 2005 are displayed. The circle marks locate those data that meet the elimination criteria. It is noted that the data with unreasonable extreme values and larger dynamic fluctuations are identified for removal.

\subsection{Feature Extraction and Analysis on Displacement Data.} The time history of the measured displacement responses can be decomposed by EMD

$$
x^{d}(t)=\sum_{j=1}^{n d} c_{j}^{d}(t)+r_{n d}^{d}(t),
$$

where $c_{j}^{d}(t)$ is the $j$ th IMF component of the displacement response; $n d$ is the total number of IMF components of displacement response; and $r_{n d}^{d}(t)$ is the final residue. The displacement responses of the bridge can be decomposed into noise component $x_{\text {noise }}^{d}(t)$, dynamic component $x_{\mathrm{dyn}}^{d}(t)$, and static component $x_{\text {static }}^{d}(t)$, respectively, with the aid of spectrum analysis

$$
\begin{gathered}
x_{\text {noise }}^{d}(t)=\sum_{j=1}^{m d} c_{j}^{d}(t), \\
x_{\mathrm{dyn}}^{d}(t)=\sum_{j=m d+1}^{n d-1} c_{j}^{d}(t),
\end{gathered}
$$

$$
\begin{aligned}
& x_{\text {static }}^{d}(t)=c_{n d}^{d}(t)+r_{n d}^{d}(t), \\
& x_{t}^{d}(t)=x_{\text {dyn }}^{d}(t)+x_{\text {static }}^{d}(t),
\end{aligned}
$$

where $m d$ is the total number of displacement IMF components of noise contamination. If the absolute mean value of a particular IMF is quite small, this IMF can be regarded as noise component. $x_{t}^{d}(t)$ denotes the nonnoise component of the displacement responses. Similar to the signal analysis of strain and temperature data, the standard deviation and the difference between the hourly maximum and minimum values are utilized to eliminate the abnormal data

$$
\begin{gathered}
\operatorname{std}\left(c_{j}^{d}(t)\right)=0, \\
\operatorname{abs}\left(x_{t, \max }^{d}-x_{t, \min }^{d}\right)>\varepsilon_{d},
\end{gathered}
$$

where $x_{t, \max }^{d}$ and $x_{t, \min }^{d}$ denote the hourly maximum and minimum displacement value, respectively; $\varepsilon_{d}$ is a real number defining the limit of the difference between the maximum and minimum values of displacement responses. An index based on the standard deviation of hourly measurement data is selected to eliminate the data substantially induced by dynamic excitation

$$
\operatorname{std}\left(x_{\mathrm{dyn}}^{d}(t)\right)>\xi_{d}
$$

where $\xi_{d}$ is the threshold value of standard deviation of a particular hourly displacement response set. Regarding selection of threshold values $\left(\varepsilon_{d}\right.$ and $\left.\xi_{d}\right)$ for the data elimination criteria, different values are individually selected for the displacement responses because they possess different measurement features and variation ranges. The threshold values obtained by trial and error are summarized in Table 2 . 
TABLE 2: Summary of threshold values for elimination criteria.

\begin{tabular}{|c|c|c|c|c|}
\hline \multirow{2}{*}{ Type of sensor } & \multirow{2}{*}{ Channel number/location } & \multirow{2}{*}{ Direction of measurement } & \multicolumn{2}{|c|}{ Threshold value } \\
\hline & & & $\varepsilon_{d}$ & $\xi_{d}$ \\
\hline \multirow{2}{*}{ Displacement transducer } & Ch. 5 & Lateral & $3 \mathrm{~mm}$ & $1 \mathrm{~mm}$ \\
\hline & Ch. 6 & Longitudinal & $100 \mathrm{~mm}$ & $20 \mathrm{~mm}$ \\
\hline \multirow{9}{*}{ GPS station } & \multirow{3}{*}{ Tower } & Longitudinal & $150 \mathrm{~mm}$ & $15 \mathrm{~mm}$ \\
\hline & & Lateral & $150 \mathrm{~mm}$ & $15 \mathrm{~mm}$ \\
\hline & & Vertical & $300 \mathrm{~mm}$ & $50 \mathrm{~mm}$ \\
\hline & \multirow{3}{*}{ Cable } & Longitudinal & $250 \mathrm{~mm}$ & $25 \mathrm{~mm}$ \\
\hline & & Lateral & $250 \mathrm{~mm}$ & $25 \mathrm{~mm}$ \\
\hline & & Vertical & $1000 \mathrm{~mm}$ & $100 \mathrm{~mm}$ \\
\hline & \multirow{3}{*}{ Deck } & Longitudinal & $150 \mathrm{~mm}$ & $15 \mathrm{~mm}$ \\
\hline & & Lateral & $150 \mathrm{~mm}$ & $15 \mathrm{~mm}$ \\
\hline & & Vertical & $1000 \mathrm{~mm}$ & $100 \mathrm{~mm}$ \\
\hline
\end{tabular}

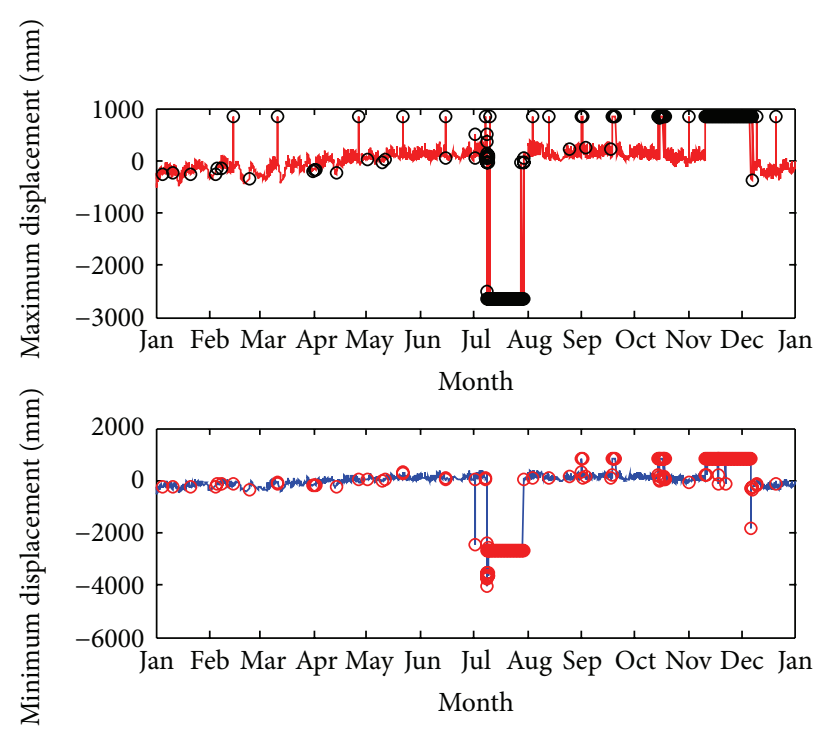

(a) Maximum and minimum displacement
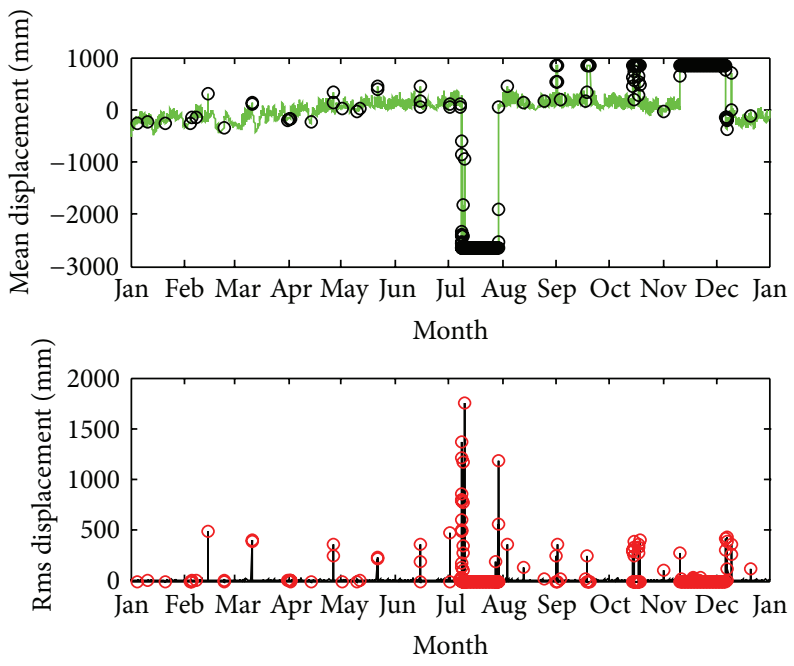

(b) Mean and rms displacement

FIGURE 10: Annual time histories of bridge longitudinal displacement in 2005 from transducer with channel number 6.

A satisfactory performance of data removal is also noted for the bridge motion measured by displacement transducers of which the time histories of the four statistical values in 2005 are shown in Figures 10(a) and 10(b). The considered displacement transducer for illustration is assigned with channel number 6 and this sensor measures the longitudinal movement of the bridge deck at the Tsing Yi abutment. It can be seen that the elimination scheme is capable of detecting all the unreasonable and undesirable data. Those measurements with zero magnitude in standard deviation, as observed in the time history in rms value, are also identified. The annual time histories of bridge vertical displacement recorded by GPS in the same period as considered in the preceding three signals are displayed in Figures 11(a) and 11(b). It is observed that the jumping of signal is the most detected abnormality in the displayed time histories compared with the measurement errors associated with the zero magnitude of standard deviation. Again, the effectiveness of the proposed indices for removal of the erroneous statistical data is clearly demonstrated. The quality of the GPS measurement can be appreciated from seldom identification of the data with error in zero standard deviation. However, overshooting of the signal is still the signal defects detected sometimes. The GPS data with standard deviation of larger value than the normal value is also commonly observed and removed. The occurrence of this case is more often than overshooting of the signal. It can be seen that the proposed several indices are capable of detecting all the unreasonable and undesirable data from the collected strain, temperature, and displacement responses. It is found that different structural responses may have different number of IMFs after being processed by using EMD. The made observations indicate that the first several IMFs are the signal components of noise contamination. Then, the following several IMFs are the signal induced by various dynamic excitations, and the last IMF and the residue are the signal mainly induced by temperature variation. 


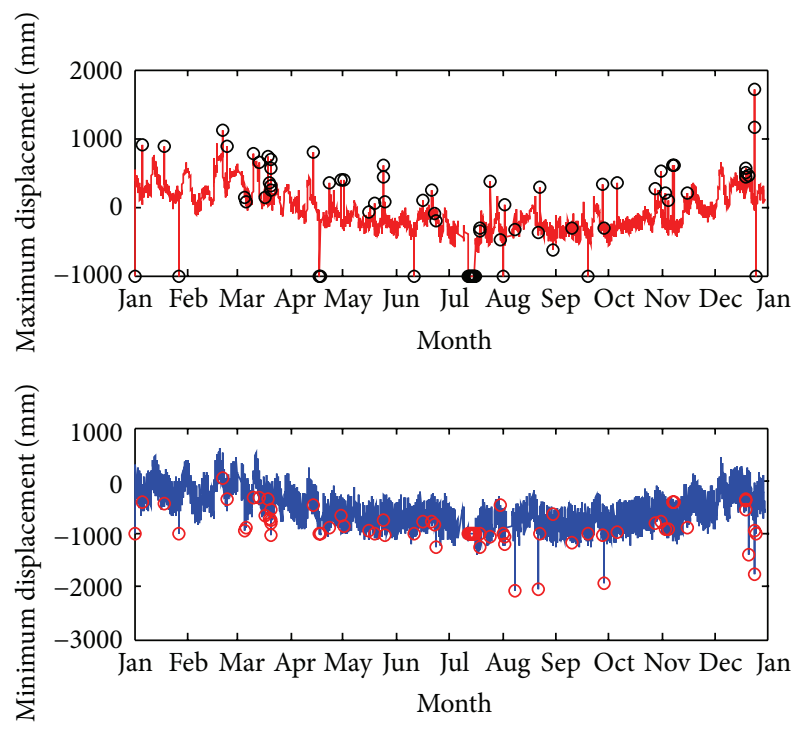

(a) Maximum and minimum displacement
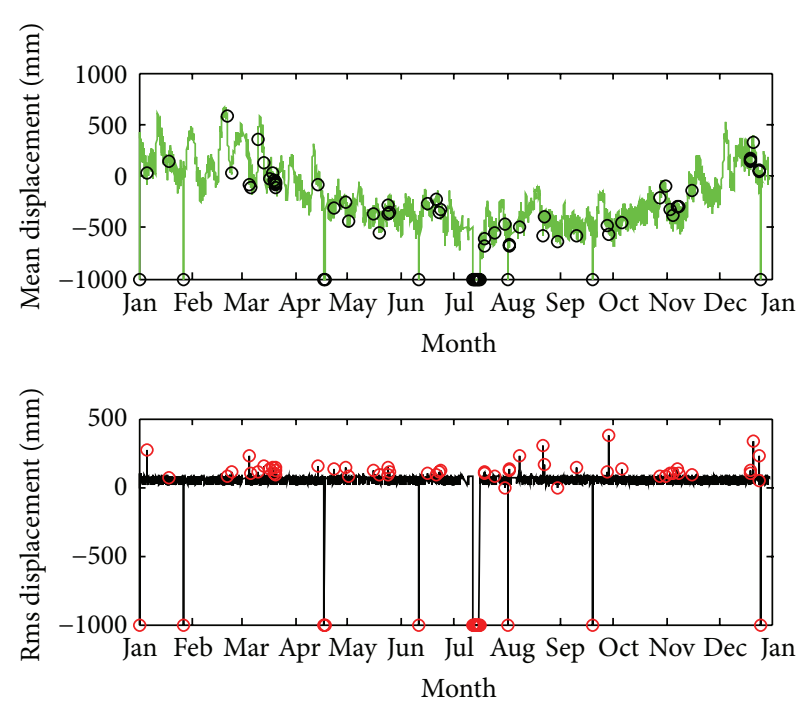

(b) Mean and rms displacement

FIGURE 11: Annual time histories of bridge vertical displacement in 2005 from GPS.

\section{Temperature Distribution}

4.1. Heat Transfer Analysis. As far as a bridge subjected to solar radiation is concerned, it is commonly assumed that thermal variation in the direction of the longitudinal axis is not significant $[8,22]$. Therefore, the temperature field $T$ of a bridge cross section can be expressed by a two-dimensional heat flow equation as

$$
k\left(\frac{\partial^{2} T}{\partial x^{2}}+\frac{\partial^{2} T}{\partial y^{2}}\right)=\rho c \frac{\partial T}{\partial t},
$$

in which $x$ and $y$ are Cartesian coordinates, $k$ is the isotropic thermal conductivity coefficient, $\rho$ is the density of material, and $c$ is the specific heat of the material. For a bridge subjected to solar radiation, the thermal energy transferred between the bridge surface and environment consists of convection $q_{c}$, thermal irradiation $q_{r}$, and solar radiation $q_{s}$ [9]. The heat flow effects induced by convection and thermal irradiation for the bridge component can be expressed as

$$
\begin{gathered}
q_{c}+q_{r}=h\left(T_{a}-T_{s}\right), \\
h=h_{c}+h_{r},
\end{gathered}
$$

where $T_{a}$ and $T_{s}$ denote the air temperature and the structural surface temperature, respectively; $h_{c}$ and $h_{r}$ denote the convection heat transfer coefficient and the radiation heat transfer coefficient, respectively.

The convection heat transfer coefficient $h_{c}$ is a function of many variables such as wind speed, surface roughness, and the geometric configuration of the exposed structure. The $h_{r}$ is a function of the emissivity coefficient of the bridge surface and the ambient temperature [9]. The rate of heat absorbed by the bridge surface due to solar radiation $q_{s}$ is $[23,24]$

$$
q_{s}=\alpha I \text {, }
$$

where $\alpha(0<\alpha<1)$ is absorptivity coefficient of the surface material; $I$ is solar radiation including direct solar radiation, diffuse solar radiation, and reflected solar radiation on a surface, respectively. The energy transferred between the surface elements and the environment is

$$
q=q_{c}+q_{r}+q_{s}
$$

Based on (20) and (25), the heat flow of a bridge surface considering solar radiation is

$$
q=h\left(T_{a}-T_{s}\right)+\alpha I
$$

or a more convenient form

$$
\begin{aligned}
& q=h\left(T^{*}-T_{s}\right), \\
& T^{*}=T_{a}+\frac{\alpha I}{h},
\end{aligned}
$$

where $T^{*}$ is usually termed as "equivalent air temperature" because it includes both the air temperature and solar radiation. In the computer analysis of a structural temperature field, the air temperature can be measured continuously as a function of time.

4.2. Temperature Distribution of Bridge. It is very difficult to establish a global model for the entire bridge and carry out the transient thermal analysis on the entire bridge due to the complicated structural configuration. Thermal variation of the bridge deck in the longitudinal direction of the bridge can be assumed insignificant and thus one typical segment is studied. Consequently, FE models of a typical deck plate, a cross frame, and a segment of the bridge tower are established using three-dimensional solid elements with the aid of commercial FE packages ANSYS (2010). The orthotropic bridge deck plate consists of steel deck plates, asphalt concrete cover, 


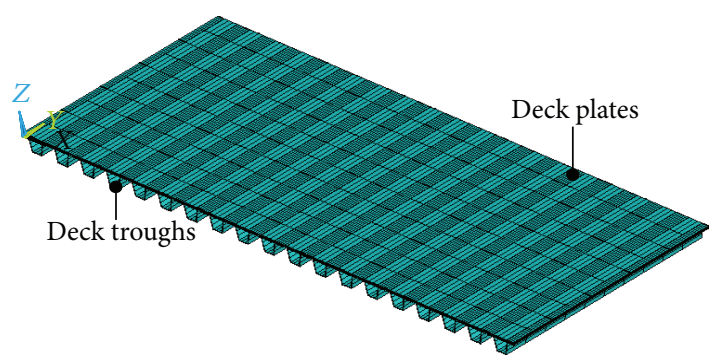

FIGURE 12: Configuration of deck plate.

and deck troughs as shown in Figure 12. The thickness of the upper and lower deck plates is $13 \mathrm{~mm}$, while the counterparts for upper deck trough and lower deck trough are $8 \mathrm{~mm}$ and $10 \mathrm{~mm}$ thick, respectively. The steel deck plates are covered by $40 \mathrm{~mm}$ asphalt concrete. The deck plates, troughs, and deck covers are modelled using thermal type solid elements. The FE model around detail 12 for heat transfer analysis consists of 24244 nodes and 18211 three-dimensional SOLID90 elements.

The transient heat transfer analysis is carried out to determine the temperature distribution of the deck plate based on the actual thermal boundary conditions The thermal conductivity of asphalt, concrete, and steel is $2.50,1.54$, and $55 \mathrm{~W} /(\mathrm{m} \cdot \mathrm{C})$, respectively. The density of asphalt, concrete, and steel is 2100,2400 , and $7800 \mathrm{~kg} / \mathrm{m}^{3}$, respectively. The heat capacity of asphalt, concrete, and steel is 960, 950, and $460 \mathrm{~J} /(\mathrm{kg} \cdot \mathrm{C})$, respectively. The absorptivity coefficient of asphalt, concrete, and steel is $0.9,0.65$, and 0.685 , respectively. The convection heat transfer coefficient $h_{c}$ can be computed in line with the wind speed and geometric configuration of deck plate by using an empirical formula [25].

The calculated temperature of the deck plate of detail 12 on summer and spring is compared with the measurement counterparts and shown in Figure 13. It is observed that the predicted temperature agrees with the measurement very well at all time points, which validates the effectiveness of the numerical model and the heat transfer analysis. The temperature of the deck plate in other two seasons is also calculated and the parameters are the same as those adopted in summer calculations except that the radiation intensity varies in different seasons. The temperature variation in autumn and winter agrees with the measurement and the results are not shown here for brevity. Similar to deck plates, the heat transfer analysis of other bridge components such as cross frame and bridge tower is also carried out. A detailed three-dimensional FE model of one cross frame is constructed consisting of 29090 nodes and 3910 threedimensional SOLID90 elements, as shown in Figure 14(a). The cross frame is modelled based on the design with minor simplification due to the omission of accessory components. The cross frame is enclosed by the deck plates and corrugate sheets, and the heat exchange occurs between the plates and the section frame. Therefore, the temperature measured at the interface between the cross frame and enclosed plates (sheets) is used as a thermal boundary condition for heat transfer computation. Other surfaces of the frame that are exposed to air do not receive solar radiation directly. Figure 14(b) indicates the detailed FE model of one tower segment with 28762 nodes and 24000 three-dimensional solid elements. The tower segment is enclosed by two semicircles and one rectangular with two rectangular holes in the middle. The depth of the tower section is $6.0 \mathrm{~m}$. Because the outer surface of the tower segment is a curve, the solar radiation on the tower surface changes with the varying node location. To facilitate the application of solar intensity, the surface of the tower is divided into 18 segments and each segment receives the same solar radiation that is calculated according to their orientation. The made observations indicate that the numerical results agree with the measurement counterparts very well at different time for the upper left chord, lower chord, and vertical truss members. Similar observations can be made from the results of tower segment, whose results are not shown here for brevity.

\section{Thermal-Structural Coupling Analysis}

5.1. Traditional Thermal-Structural Coupling Analysis. A global FE model of the entire bridge is constructed as shown in Figure 15(a) for structural analysis to compute the temperature-induced responses. Components are simplified appropriately and modelled with relatively coarse meshes in the structural analysis as compared with the heat transfer analysis. Regarding the FE model of the entire Tsing $\mathrm{Ma}$ Bridge, all the frame components and longitudinal trusses are modelled as beam elements that are appropriately meshed for connections with highway decks and railway tracks. The configuration of a typical bridge section in the concerned FE model of the entire bridge is displayed in Figure 15(b). It is seen that there are sixteen nodes in the section and nineteen beam elements are adopted to construct a single bridge section. Shell elements are utilized to simulate the upper and lower orthotropic deck plates. The bracing, railway beam, and other longitudinal members are also constructed with beam or bar elements. Since the highway decks and railway tracks are vertical at different levels with the cross frames and longitudinal trusses, multipoint constraints (MPCs) are used to connect them to simulate the master-slave relationship. The bridge towers, piers are simulated by using threedimensional solid elements. The suspensors and main cables are also model by using bar elements. The entire model has 23960 nodes and 28856 elements. Totally 4788 MPCs are also used for connections between the orthotropic deck plates and the chords of cross frames.

The computation of bridge thermal effects is a typical thermal-structural coupling analysis because the temperature distribution is calculated firstly and then taken as the loading on the bridge model to determine the temperatureinduced responses such as displacement and strain. In the FE computation, the thermal-structural coupling analysis is carried out by using the sequential coupling method [26]. In the application of this approach, the heat transfer analysis is conducted firstly to determine the structural temperature fields, and all the thermal information is stored in thermal database. Then, the nodal temperature loading is taken as body loading of the model to compute the structural 


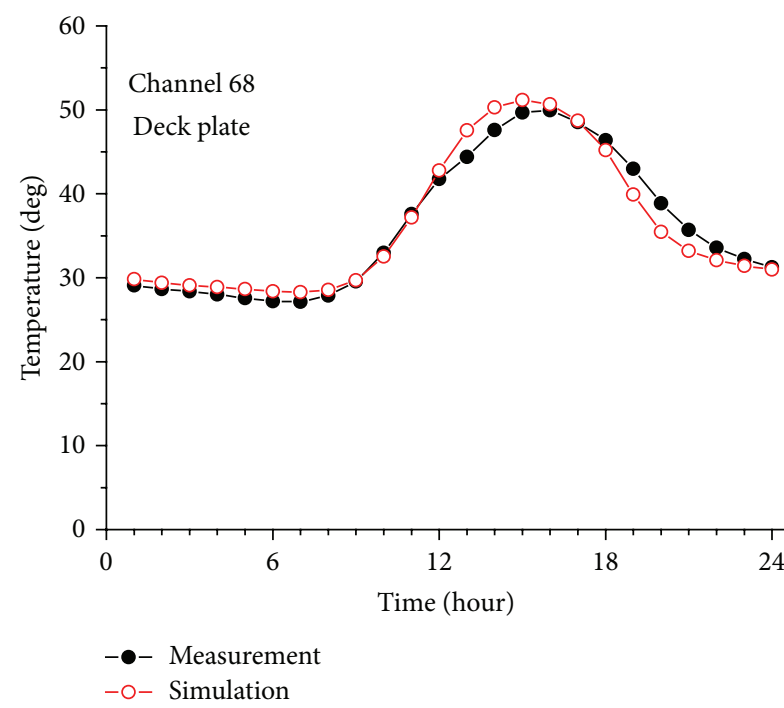

(a) Summer (July 17, 2005)

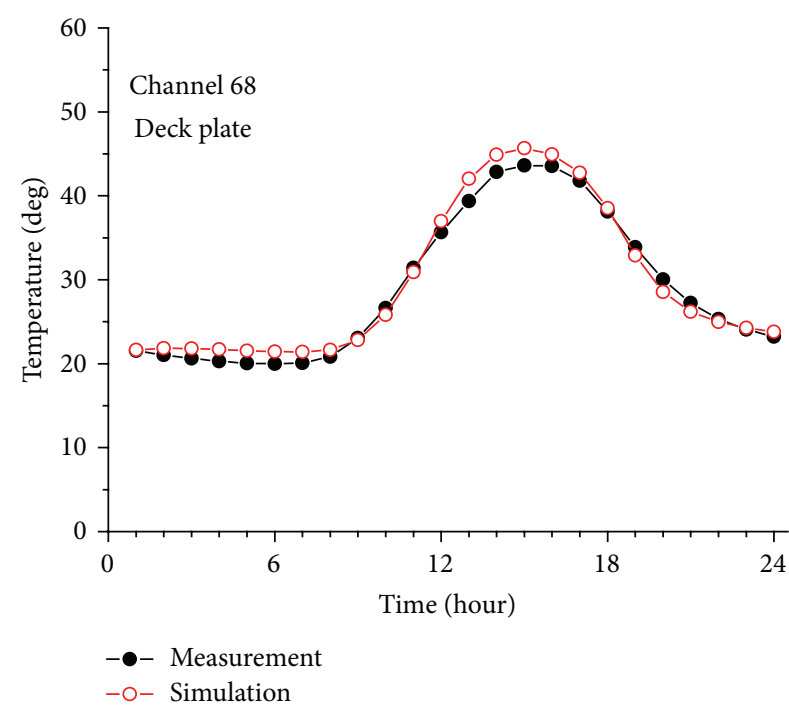

(b) Spring (April 18, 2005)

FIGURE 13: Comparison of the measured and simulated temperature at detail 12 in spring.

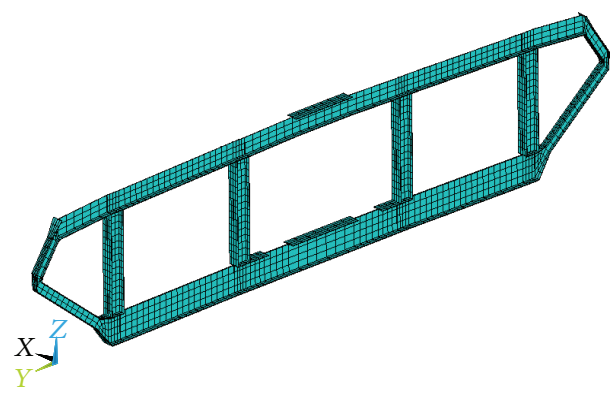

(a) Cross frame

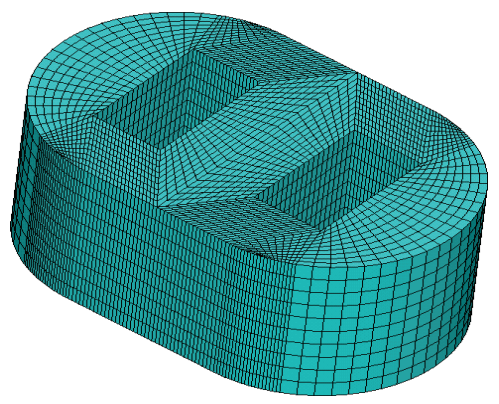

(b) Tower segment

FIGURE 14: Finite element models of bridge components.

responses. It is clear that the heat transfer analysis and structural analysis are performed based on thermal FE model with thermal element and structural FE model with structural elements, respectively. However, the number of nodes and elements of the two models should be the same to transfer the nodal temperature to nodal thermal loading one by one. This is a very important precondition for the sequential coupling method in the thermal-structural coupling analysis [26]. In reality, the sequential coupling method only can be successfully applied to the structural model with small scales instead of large-scale structures such as the Tsing Ma Bridge.

The detailed FE models of a deck plate, a cross frame, and a tower segment for heat transfer analysis are described and plotted in Figures 12 and 14, respectively. Fine meshes are required for these models to compute the exact temperature fields and thus the large number of nodes and elements can be expected. Therefore, the models of a deck plate, a cross frame, and a tower segment for thermal effect analysis should have the same scales by using the sequential coupling method. The Tsing Ma Bridge has hundreds of cross frames and thousands of deck plates. Therefore, there may exist about two million nodes and elements in the entire bridge model constructed by the heat transfer model and solved by the sequential coupling method. In reality, the FE model of the entire bridge with a remarkably large scale is unreasonable and time consuming for the current structural analytical technique. To this end, a new approach for thermal-structural coupling analysis of long span bridge is proposed and applied to the Tsing $\mathrm{Ma}$ Suspension Bridge.

\subsection{A New Approach for Thermal-Structural Coupling Anal-} ysis. As discussed above, pretty complicated FEM models are not necessary when examining the global temperatureinduced structural responses of the entire bridge. Therefore, a simplified analytical model with an appropriate dimension is expected for balancing satisfactory accuracy and analytical expense. Thus, the three-dimensional FE model of the Tsing Ma bridge as shown in Figure 15 is utilized for thermal effect analysis. Because the sizes of the FE model for heat transfer analysis are much larger than those for response analysis, the size of the temperature loading from the heat transfer analysis is very large and cannot be applied directly to 


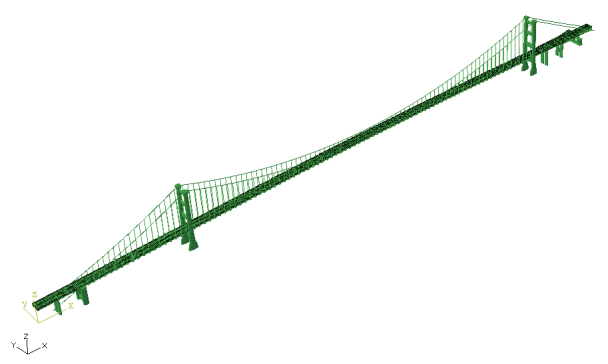

(a) Global model

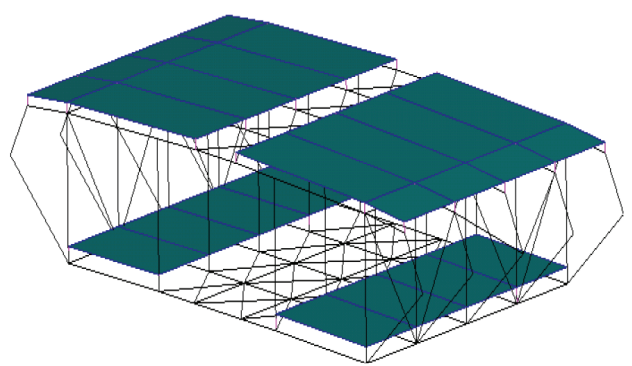

(b) Deck module

FIgURE 15: Finite element model of the Tsing Ma bridge.

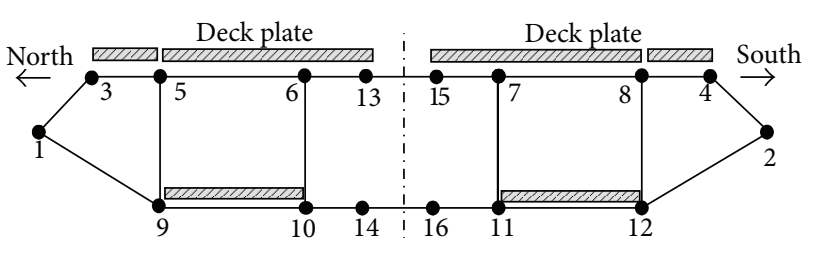

FIgURE 16: Configuration of a cross frame in the global model.

the global model due to its small node dimension. To analyze the thermal responses of the entire bridge, the temperature loading should be applied to the global bridge model. It is found that the node number of single cross frame based on the thermal solid model (Figure 15) is 23960, while the node number of the same frame for structural analysis is only 19 as shown in Figure 16. Therefore, the equivalent temperature loading can be constructed for thermal response assessment by using the concept of effective temperature.

The effective temperature is proposed to study the measured temperatures of the bridge deck section and the main cable section [19]. The effective temperature is considered instead of the temperature measured from any single sensor in the cross section concerned. The effective temperature is a theoretical temperature calculated by weighting and adding temperatures measured at various locations within the cross section. The weighting is the ratio of the area of cross section for a particular sensor to the total area of cross section

$$
T_{E}=\frac{\int T d A}{A} .
$$

The effective deck temperature and effective cable temperature are indices to depict the integral temperature effects of bridge decks and bridge cables. Thus, an index named effective nodal temperature is proposed in this study to construct the nodal temperature loadings for the thermal effect analysis. The effective nodal temperature for a node $i$ in bridge deck $T_{i}^{\text {deck }}$ is a temperature calculated by weighting and adding temperatures obtained at various locations within the volume affiliated to node $i$. The weighting is the ratio of the volume of the section for a particular node $i$ to the total volume of the cross frame section

$$
T_{i}^{\text {deck }}=\frac{\sum_{j=1}^{n f} T_{j}^{f} V_{j}^{f}+\sum_{j=1}^{n p} T_{j}^{p} V_{j}^{p}+\sum_{j=1}^{n b} T_{j}^{b} V_{j}^{b}}{\sum_{j=1}^{n f} V_{j}^{f}+\sum_{j=1}^{n p} V_{j}^{p}+\sum_{j=1}^{n b} V_{j}^{b}},
$$

where $n f, n p$, and $n b$ denote the numbers of volume elements of cross frame, deck plate, and truss brace affiliated to node $i ; V_{j}^{f}, V_{j}^{p}$, and $V_{j}^{b}$ denote the volume of the $j$ th element of cross frame, deck plate, and brace affiliated to node $i ; T_{j}^{f}, T_{j}^{p}$, and $T_{j}^{b}$ denote the temperature of the $j$ th element of cross frame, deck plate, and brace affiliated to node $i$. Similarly, the effective nodal temperature for a node $i$ in bridge tower $T_{i}^{\text {tower }}$ and bridge cable $T_{i}^{\text {cable }}$ can be expressed as

$$
\begin{gathered}
T_{i}^{\text {tower }}=\frac{\sum_{j=1}^{n t} T_{j}^{t} V_{j}^{t}}{\sum_{j=1}^{n t} V_{j}^{t}}, \\
T_{i}^{\text {cable }}=\frac{\sum_{j=1}^{n c} T_{j}^{c} V_{j}^{c}}{\sum_{j=1}^{n c} V_{j}^{c}},
\end{gathered}
$$

where $n t$ and $n c$ denote the numbers of volume elements of tower segment and cable affiliated to node $i ; V_{j}^{t}$ and $V_{j}^{c}$ denote the volume of the $j$ th element of tower segment and cable affiliated to node $i$; $T_{j}^{t}$ and $T_{j}^{c}$ denote the temperature of the $j$ th element of tower segment and cable affiliated to node $i$.

The element affiliation to a certain node $i$ can be evenly divided according to geometric position as shown in Figure 16 for simplification. Thus, the effective temperature loading of the bridge at different time instant $\mathbf{T}^{E}(t)$ is computed and expressed as

$$
\mathbf{T}^{E}(t)=\left[\mathbf{T}^{\text {deck }}(t), \mathbf{T}^{\text {tower }}(t), \mathbf{T}^{\text {cable }}(t)\right] .
$$

The thermal expansion coefficients of concrete and steel can be adopted based on material properties in the thermal analysis. It is reported above that the orthotropic plate of the Tsing Ma Bridge is constructed with steel plate, steel trough, and asphalt concrete cover. The bridge plates, however, are simulated by using shell elements in the global FE model; therefore, an equivalent thermal expansion coefficient for the deck plate with the trough and cover is proposed. To assume that the thermal expansion of the real plate is equal to that of the simulated shell element subjected to same effective plate temperature, one can obtain that

$$
\alpha_{E}^{P} T_{E}^{c P}\left(A_{c}+A_{s}\right)=\alpha_{c} T_{E}^{c P} A_{c}+\alpha_{s} T_{E}^{c P} A_{s}
$$

in which $\alpha_{c}$ and $\alpha_{s}$ are the thermal expansion coefficients of concrete and steel, respectively; $\alpha_{E}^{P}$ is the equivalent thermal 

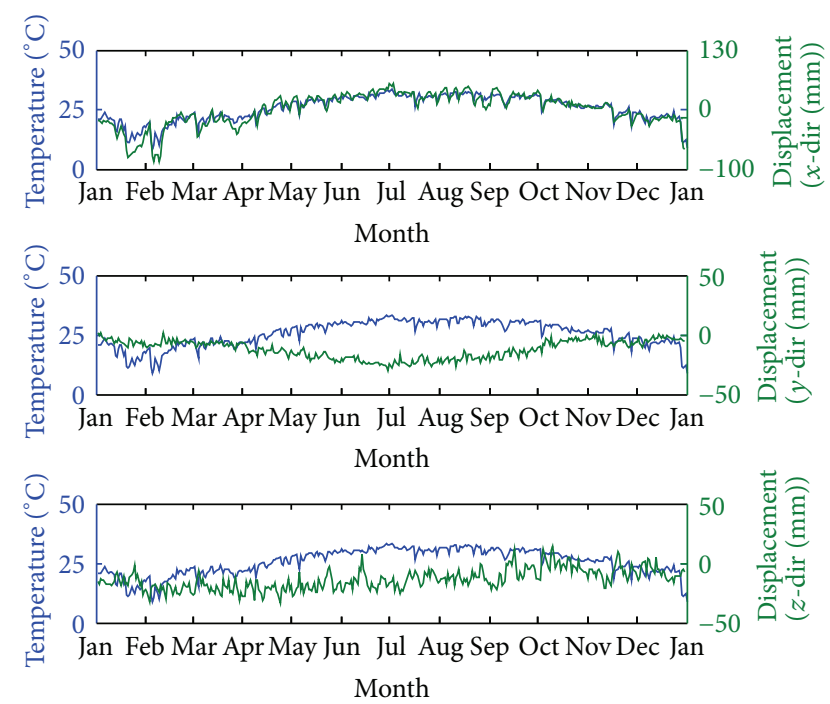

FIGURE 17: Comparison of effective cable temperature and displacement of the Ma Wan tower in 2004.

expansion coefficient of shell elements; $T_{E}^{c P}$ is the effective temperature of the orthotropic deck plate; $A_{c}$ and $A_{s}$ are the concrete area and steel area in cross section, respectively. Then, the equivalent thermal expansion coefficient is given by

$$
\alpha_{E}^{P}=\frac{\alpha_{c} A_{c}+\alpha_{s} A_{s}}{\left(A_{c}+A_{s}\right)} .
$$

\section{Temperature Effects of the Bridge}

6.1. Displacement of the Bridge. To gain a better understanding towards different parts of the bridge movement in the three orthogonal directions, the variation ranges and patterns of bridge displacement responses are investigated. In this regard, the extent of temperature effects on the bridge displacement in the three different directions is unveiled in this section. The displacement of the Ma Wan tower in the three directions in comparison with the effective cable temperature is carried out and displayed in Figure 17. The displacement is the average value, which is performed by WASHMS and provided in the original records, based on the measurements from the two stations. It can be seen that only the displacement in the $x$-direction (longitudinal) shows a good agreement with the effective deck temperature. The lateral ( $y$-dir.) and vertical ( $z$-dir.) displacements are small and seem to be not well correlated with the effective cable temperature and are thus not dominantly affected by the temperature. Moreover, the displacements of the Tsing Yi tower in the three directions are also analyzed and similar conclusions to those of the Ma Wan tower can be drawn out. The longitudinal displacement of the bridge deck recorded by displacement transducers from 2003 to 2005 is displayed in Figure 18 in comparison with the effective deck temperature. It is observed that the longitudinal displacement at the Tsing Yi abutment shows a good agreement with the effective deck temperature.
The displacements of the bridge deck in the $1 / 4$ span of the main span from the Ma Wan tower (MWMS) on July 17, 2005, are computed and compared with measurement as shown in Figure 19. The curves indicate that the displacements in the $x$-(longitudinal) and $z$-(vertical) directions show a good agreement with the measurement. The lateral ( $y$-dir.) displacement is noted to be independent of the temperature and is thus not affected by the temperature. Similar observations can be made from the results at main span, side span, and the bridge tower which are not displayed for brevity. It is observed that only the simulated hourly displacement variations in the longitudinal direction at Ma Wan side span MWSS show a good agreement with the measured hourly displacement variations. The lateral ( $y$-dir.) and vertical ( $z$-dir.) hourly displacement variations seem to be not well correlated with the temperature and are thus not dominantly affected by the temperature. The results from wind excited dynamic analysis indicate that the lateral responses are mainly induced by wind, in particular dynamic wind loadings.

6.2. Stress of the Bridge. The variation in stresses on bridge members is investigated in this section. Considering that temperature tends to cause static strain of the bridge whereas traffic loadings cause dynamic strain, hourly mean strain is calculated and regarded due to temperature variation. For the axial loaded members, the stress is calculated from the strain by multiplying Young's modulus of steel, $2.01 \times$ $10^{11} \mathrm{~Pa}$. Take the north inner longitudinal truss at Figure 4 as an example. The strains at the upper chord, diagonal brace, and bottom chord are measured by strain gauges. Their hourly mean stresses from the measurement data on July 17, 2005, are shown in Figure 20 in comparison with the numerical counterparts. It is noted that the strain induced by moving train loadings has been removed from the original time histories by using the proposed data process approach. The figure shows that the calculated stresses agree well with the field measurements, indicating that the stress variation is mainly caused by the temperature changes. The temperature-induced stresses are about $10 \mathrm{MPa}$ in maximum, much smaller than the design strength of steel. Therefore, the proposed new approach can successfully conduct the thermal-structural coupling analysis of the long span bridge.

\section{Concluding Remarks}

The condition assessment on temperature distribution and thermal effects of the Tsing Ma Suspension Bridge is carried out in this study. The data collected from the SHM system are processed with the aid of empirical mode decomposition (EMD). The signal components induced by dynamic excitations and noise are extracted from the original data time histories. Several indices are proposed to process the timevarying temperature, displacement, and strain responses obtained by SHM system. The heat transfer analysis of the bridge is conducted to calculate the temperature distributions within the bridge. By assuming that the temperature along the bridge longitudinal direction is constant, one typical bridge segment is specially studied. A similar assumption is applied to the towers. Fine FE models of various components such 


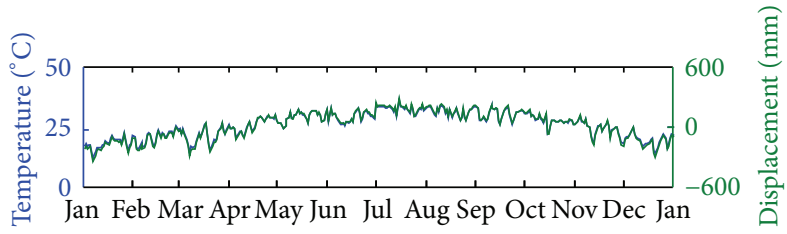

(a) Year 2003

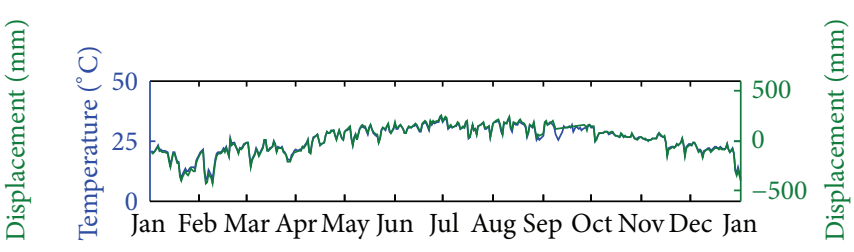

(b) Year 2004

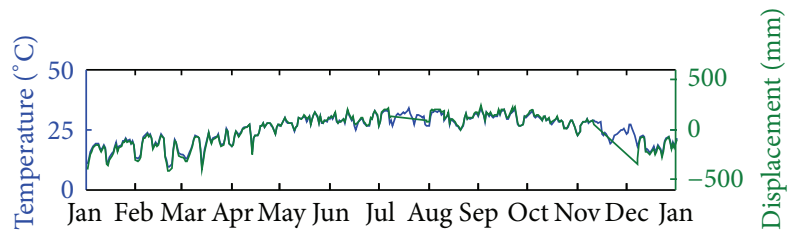

(c) Year 2005

FIGURE 18: Comparison of effective deck temperature and longitudinal displacement at the Tsing Yi abutment.
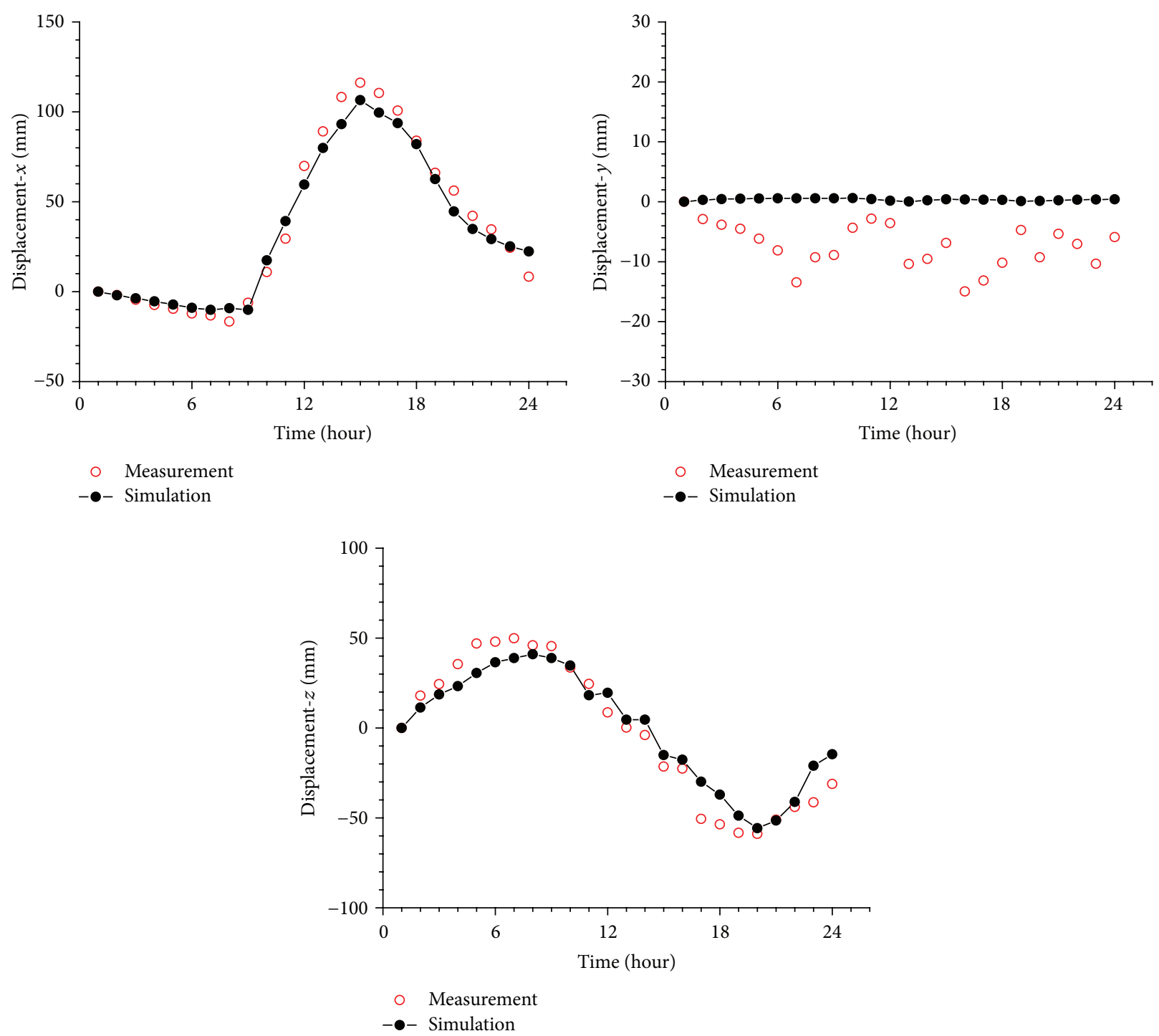

FIGURE 19: Displacement of the bridge deck (MWMS) with respect to time tower in 2004. 

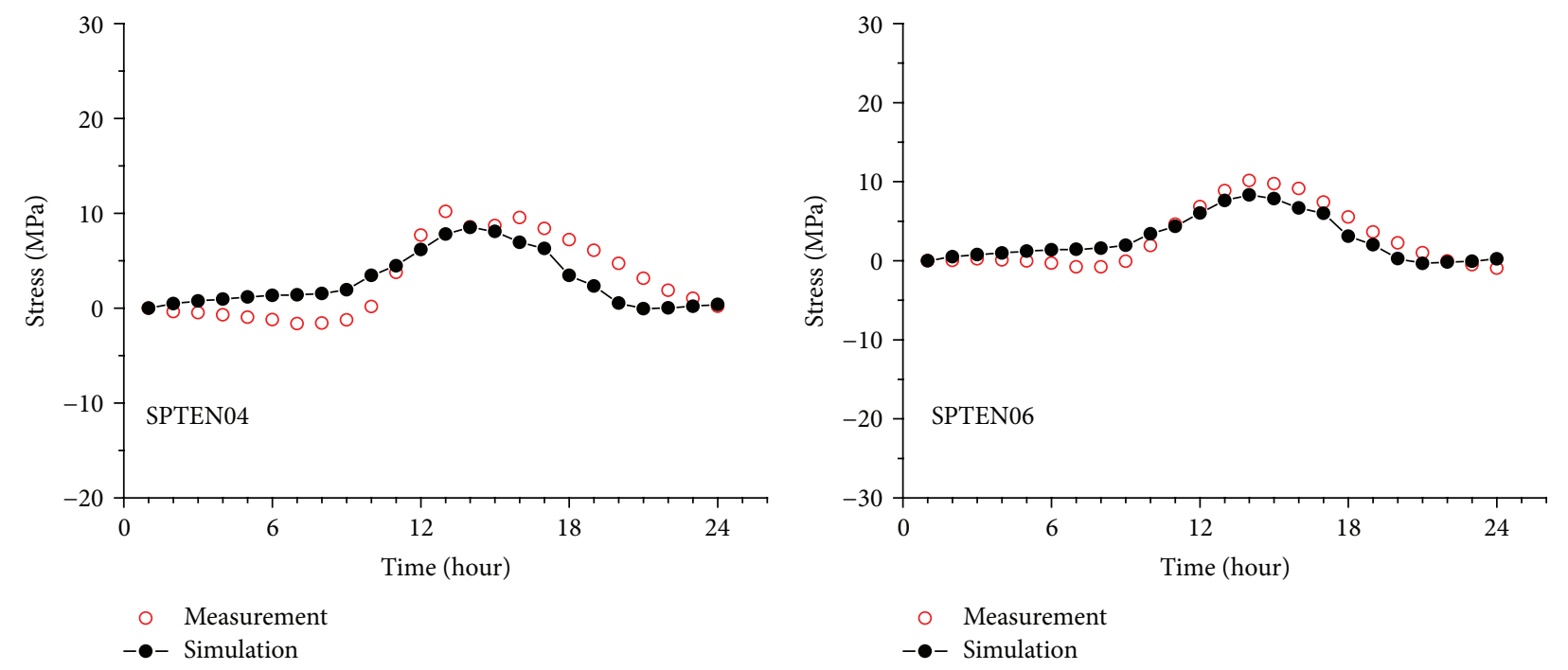

FIGURE 20: Variations of member stresses with respect to time.

as the deck plate, the frame section, and the tower section are constructed. A new approach for the thermal-structural coupling analysis of long span bridges is proposed to examine the structural thermal effects. The feasibility and validity of the proposed data process approach and the new approach for thermal-structural coupling analysis are examined through detailed simulation and comparison.

The made observation indicates that the proposed data processing approach can successfully eliminate the noise components from the original data sets. It can be seen that the proposed several indices are capable of detecting all the unreasonable and undesirable data from the collected strain, temperature, and displacement responses. The proposed analytical model and approach can successfully predict the structural temperature of various components at different time. The approach for thermal-structural coupling analysis established in this study can be successfully applied in the assessment of the thermal effects of the Tsing Ma Suspension Bridge. It should be pointed out that the parameters and results are valid only for the example building examined in this study. For other bridges with different parameters, the methodology for the signal processing and thermal effect assessment demonstrated in this study is still valid.

\section{Acknowledgments}

The writers are grateful for the financial support from the National Natural Science Foundation of China (51178366), the Fundamental Research Funds for the Central Universities (WUT, 2013-II-015), and the Technological Project of the Chinese Southern Power Grid Co. Ltd (K-GD2013-0222).

\section{References}

[1] O. S. Salawu, "Detection of structural damage through changes in frequency: a review," Engineering Structures, vol. 19, no. 9, pp. 718-723, 1997.
[2] T. Yi, H. Li, and M. Gu, "Full-scale measurements of dynamic response of suspension bridge subjected to environmental loads using GPS technology," Science China Technological Sciences, vol. 53, no. 2, pp. 469-479, 2010.

[3] T. H. Yi, H. N. Li, and M. Gu, "Experimental assessment of high-rate GPS receivers for deformation monitoring of bridge," Measurement, vol. 46, no. 1, pp. 420-432, 2013.

[4] W. Zuk, "Thermal behaviour of composite bridges-insulated and uninsulated," Highway Research Record, vol. 76, pp. 231-253, 1965.

[5] M. W. R. Capps, "The thermal behavior of the Beachley Viaduct/Wye Bridge," Tech. Rep. TRRL Report LR 234, Ministry of Transport, Road Research Laboratory, 1968.

[6] A. Churchward and Y. J. Sokal, "Prediction of temperatures in concrete bridges," Journal of Structural Division, vol. 107, no. 11, pp. 2163-2176, 1981.

[7] M. J. N. Priestley, "Design of concrete bridges for thermal gradients," ACI Journal, vol. 75, no. 5, pp. 209-217, 1978.

[8] M. M. Elbadry and A. Ghali, "Temperature variation in concrete bridges," Journal of Structural Engineering, vol. 109, no. 10, pp. 2355-2374, 1983.

[9] F. A. Branco and P. A. Mendes, "Thermal actions for concrete bridge design," Journal of Structural Engineering, vol. 119, no. 8, pp. 2313-2231, 1993.

[10] M. A. Shahawy and M. Arockiasamy, "Analytical and measured strains in sunshine skyway bridge. II," Journal of Bridge Engineering, vol. 1, no. 2, pp. 87-97, 1996.

[11] C. L. Roberts-Wollman, J. E. Breen, and J. Cawrse, "Measurements of thermal gradients and their effects on segmental concrete bridge," Journal of Bridge Engineering, vol. 7, no. 3, pp. 166-174, 2002.

[12] Y. Fu and J. T. DeWolf, "Effect of differential temperature on a curved post-tensioned concrete bridge," Advances in Structural Engineering, vol. 7, no. 5, pp. 385-397, 2004.

[13] S. L. Desjardins, N. A. Londoño, D. T. Lau, and H. Khoo, "Realtime data processing, analysis and visualization for structural monitoring of the confederation bridge," Advances in Structural Engineering, vol. 9, no. 1, pp. 141-157, 2006. 
[14] M. Tong, F. T. K. Au, L. G. Tham, and K. Y. Wong, "A study of temperature measurement in long span steel bridge," in Proceedings of the Workshop on Research and Monitoring of long Span Bridges, pp. 188-195, Hong Kong, 2000.

[15] M. Tong, L. G. Tham, F. T. K. Au, and P. K. K. Lee, "Numerical modelling for temperature distribution in steel bridges," Computers and Structures, vol. 79, no. 6, pp. 583-593, 2001.

[16] F. T. K. Au, L. G. Tham, M. Tong, and P. K. K. Lee, “Temperature monitoring of steel bridges," in Health Monitoring and Management of Civil Infrastructure Systems, vol. 4337 of Proceedings of SPIE, pp. 282-291, Newport Beach, Calif, USA, March 2001.

[17] K. Y. Wong, C. K. Lau, and A. R. Flint, "Planning and implementation of the structural health monitoring system for cablesupported bridges in Hong Kong," in Nondestructive Evaluation of Highways, Utilities, and Pipelines IV, vol. 3995 of Proceedings of SPIE, pp. 266-275, Newport Beach, Calif, USA, March 2000.

[18] K. Y. Wong, D. K. L. Man, and K. W. Y. Chan, “Thermal load and response monitoring of Ting Kau (Cable-Stayed) bridge," in Proceedings of the International Conference on Innovation and Sustainable Development of Civil Engineering in the 21st Century, pp. 249-252, Beijing, China, August 2002.

[19] Y. L. Xu, B. Chen, C. L. Ng, K. Y. Wong, and W. Y. Chan, "Monitoring temperature effect on a long suspension bridge," Structural Control and Health Monitoring, vol. 17, no. 6, pp. 632653, 2010.

[20] T. H. Yi, H. N. Li, and M. Gu, "Wavelet based multi-step filtering method for bridge health monitoring using GPS and accelerometer," Smart Structures and Systems, vol. 11, no. 4, pp. 331-348, 2013.

[21] B. Chen and Y. L. Xu, "A new damage index for detecting sudden change of structural stiffness," Structural Engineering and Mechanics, vol. 26, no. 3, pp. 315-341, 2007.

[22] H. C. Fu, S. F. Ng, and M. S. Cheung, "Thermal behavior of composite bridges," Journal of Structural Engineering, vol. 116, no. 12, pp. 3302-3323, 1989.

[23] W. M. Rohsenow, Handbook of Heat Transfer Applications, McGraw-Hill, New York, NY, USA, 1988.

[24] F. Kehlbeck, Einfluss der Sonnenstrahlung cei Bruckenbauwerken, Werner, Dusseldorf, Germany, 1975.

[25] M. Froli, N. Hariga, G. Nati, and M. Orlandini, "Longitudinal thermal behaviour of a concrete box girder bridge," Structural Engineering International, vol. 6, no. 4, pp. 237-242, 1996.

[26] ANSYS 11.0, ANSYS, Southpointe, Pa, USA, 2010. 


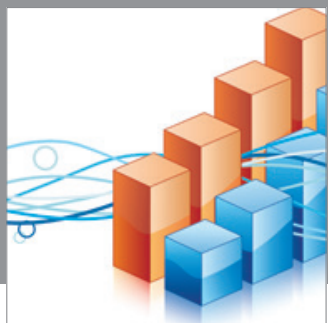

Advances in

Operations Research

mansans

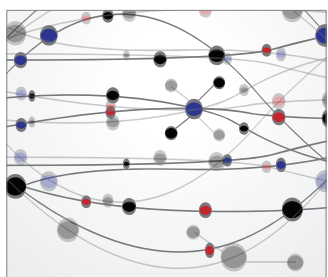

The Scientific World Journal

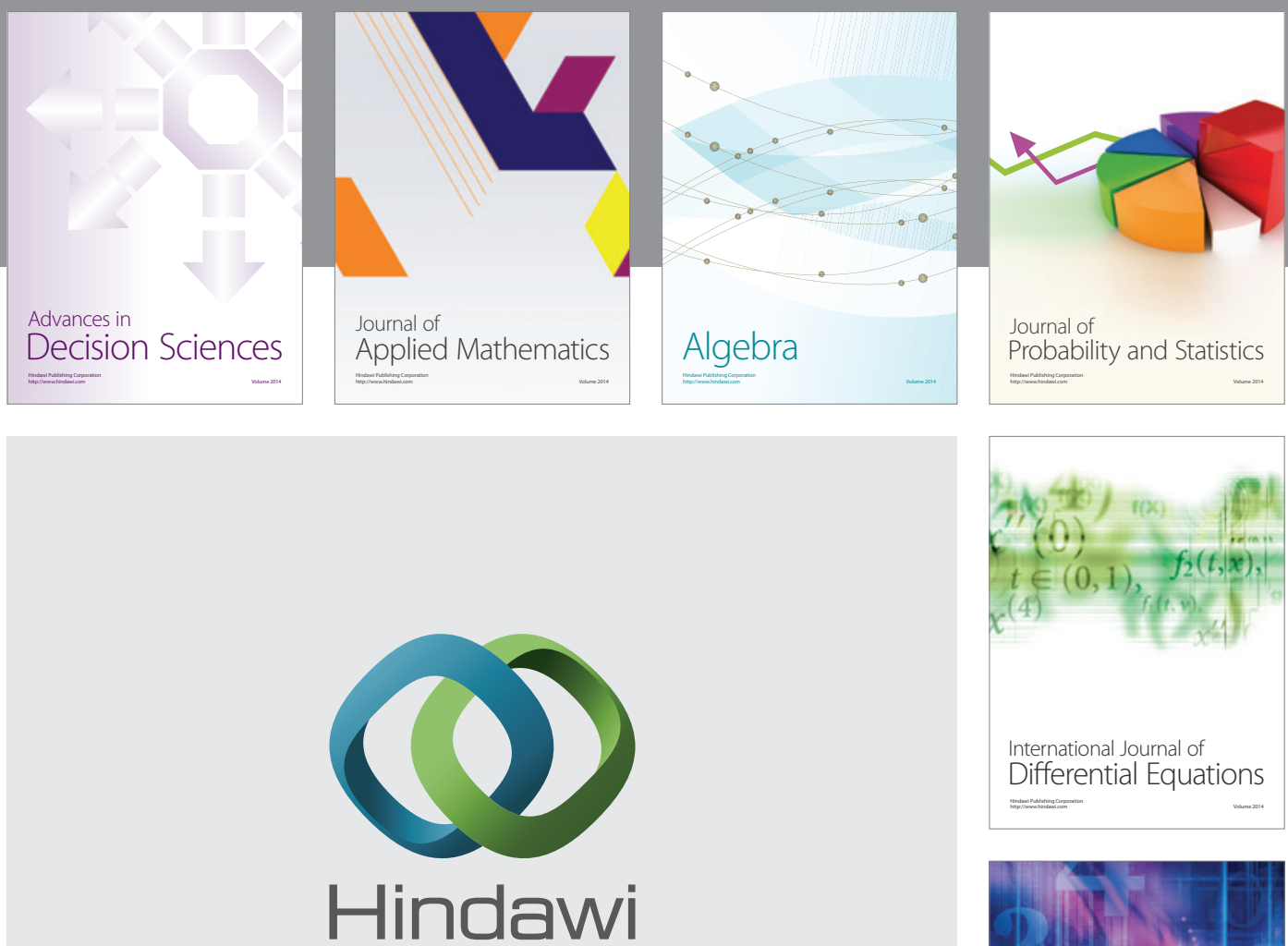

Submit your manuscripts at http://www.hindawi.com
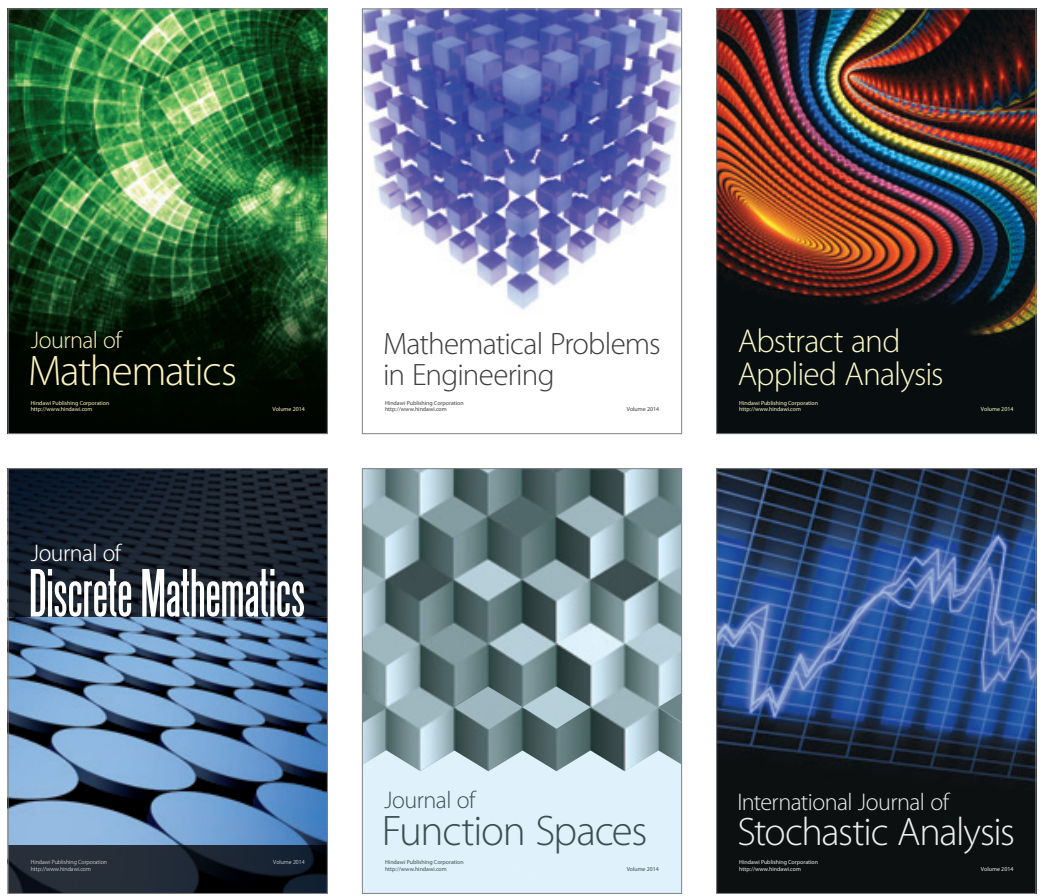

Journal of

Function Spaces

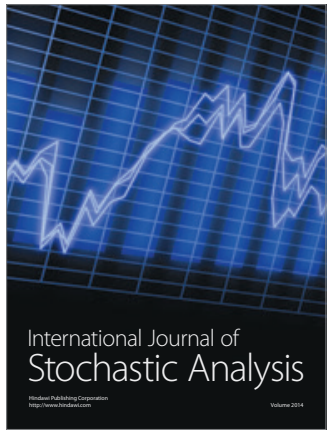

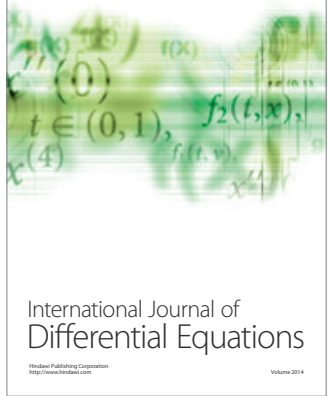
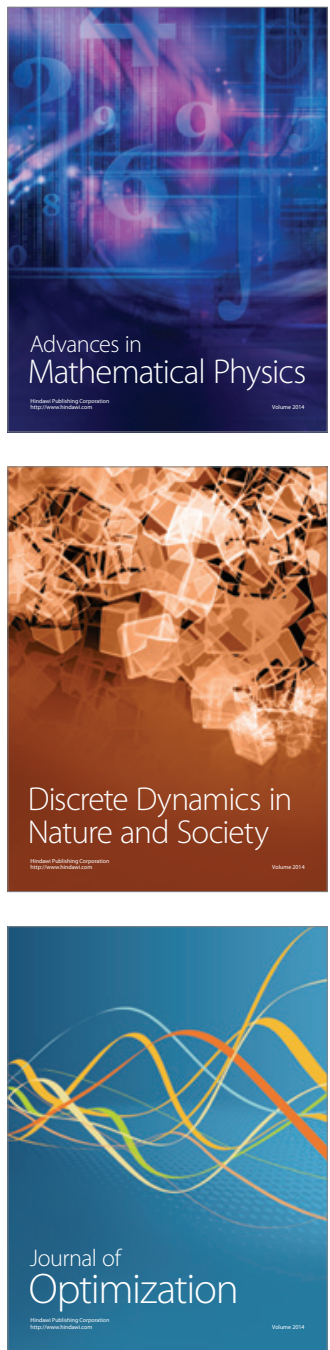